\title{
Heart Best Research Paper Award 2021
}

Each year, the Heart editorial team selects the most meritorious research paper to receive the Heart Best Research Paper Award. Primary considerations are the relevance of the clinical question addressed by the research, the quality of the research study design and data presentation and the interest generated by the paper among other researchers, clinical cardiologists and the general public.

This year, we are pleased to announce the winner and two finalists for the 2021 Heart Best Paper Research Award, highlighting the first author of each paper and sincerely congratulating the entire research team on their outstanding research contribution (table 1). Each of the authors contributed the text below summarising their background, research goals and the key findings of these studies.

\section{WINNER}

Julia Hippisley-Cox (figure 1) is Professor of Clinical Epidemiology and General Practice at the University of Oxford and an NHS GP in Oxfordshire. She undertakes research to advance understanding of many diseases using routinely collected large-scale linked electronic health records. She is particularly interested in translational research where the results can lead to improvements in patient care and the health services. She established the QResearch database of primary care records, which was linked to hospital, mortality and cancer registry.

At the start of the pandemic, there was uncertainty about the interaction of angiotensin converting enzyme (ACE) inhibitor and angiotensin receptor blocker (ARB) drugs with COVID-19 susceptibility and disease severity. The team therefore extended this database resource to include SARS-CoV-2 test results and intensive care data from the Intensive Care National Audit \& Research Centre (ICNARC in order to undertake a very large population-based study to answer this. The study found that treatment with ACE inhibitor and ARB prescriptions was associated with a reduced risk ofRTPCR-positive COVID-19 after adjusting for a wide range of variables. Neither

Correspondence to Professor Catherine M Otto, Division of Cardiology, University of Washington, Seattle, Washington, USA; cmotto@uw.edu

ACE inhibitors nor ARBs were associated with increased risks of receiving intensive care unit care for COVID-19. There were significant interactions with ethnicity for ACE inhibitors and ARBs for COVID-19 with higher risks among the non-white ethnic groups particularly Black African patients compared with the white group, although the CIs for some analyses are wide. This finding is important and adds to existing knowledge. Variations between different ethnic groups raise the possibility of ethnic-specific effects of ACE inhibitors/ARBs on COVID-19 susceptibility and severity.

\section{FINALISTS}

Åsa K Hedman (figure 2) is a computational scientist at Pfizer Worldwide Research, Development and Medical, with a keen interest in applying statistical and computational methods to high-dimensional genetic, molecular and clinical data to advance understanding of human disease in order to aid drug target discovery and definition of patient subpopulations. She received her $\mathrm{PhD}$ from Imperial College London, followed by postdoctoral positions at University of Oxford, Uppsala University and Karolinska Institute.

In this research paper, a machine learning clustering model was used to identify six phenotype subgroups among 320 patients with heart failure with preserved ejection fraction (HFpEF). These distinct HFpEF

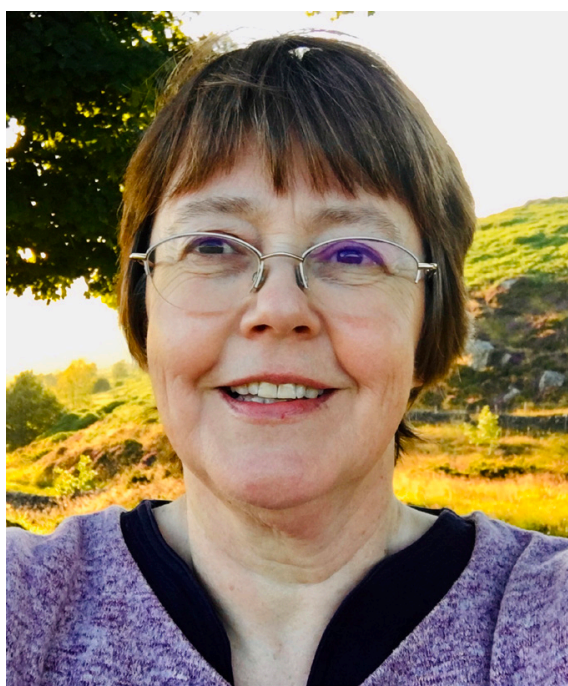

Figure 1 Julia Hippisley-Cox.

phenotype groups showed differential clinical characteristics, as well as differences in plasma proteins that included biomarkers for heart failure, atrial fibrillation and kidney disease. In addition, the composite clinical outcomes varied with the highest rates of all-cause mortality and heart failure hospitalisation in phenogroup 1 , all of whom had hypertension with high prevalence of coronary artery disease, kidney dysfunction, anaemia and diabetes, and phenogroup 2, most of whom had atrial fibrillation with a high prevalence of chronic obstructive lung disease, older

Table 1 Heart Best Research Paper Award winner and finalists 2020

\section{Winner}

Julia Hippisley-Cox, Duncan Young, Carol Coupland Keith M Channon, Pui San Tan, David A Harrison, Kathryn Rowan, Paul Aveyard, Ian D Pavord, Peter J Watkinson

\section{Finalists}

Åsa K. Hedman, Camilla Hage, Anil Sharma, Mary Julia Brosnan, Leonard Buckbinder, Li-Ming Gan, Sanjiv J Shah, Cecilia M Linde, Erwan Donal, Jean-Claude Daubert, Anders Mälarstig, Daniel Ziemek, Lars Lund

Gal Tsaban, Anat YaskolkaMeir, Ehud Rinott, Hila Zelicha, Alon Kaplan, Aryeh Shalev, Amos Katz, Assaf Rudich, Amir Tirosh, Ilan Shelef, Ilan Youngster, Sharon Lebovitz, Noa Israeli, May Shabat, Dov Brikner, Efrat Pupkin, Michael Stumvoll, Joachim Thiery, Uta Ceglarek, John T Heiker, Antje Körner, Kathrin Landgraf, Martin von Bergen, Matthias Blüher, Meir J Stampfer, Iris Shai Mediterranean diet on
Risk of severe COVID-19 with ACE inhibitors and angiotensin receptor blockers: cohort study including 8.3 million people. July 2020.

Heart Oct 2020, 106 (19) 1503-1511; DOI: 10.1136/ heartjnl-2020-317393. Published Online First 31

Identification of novel pheno-groups in heart failure with preserved ejection fraction using machine learning.

The effect of green cardiometabolic risk; a randomised controlled trial.
Heart Mar 2020, 106 (5) 342-349; DOI: 10.1136/ heartjnl-2019-31548. Published Online First 7 January 2020.

Heart Jul 2021, 107 (13) 1054-1061; DOI: 10.1136/ heartjnl-2020-317802.

Published Online First 23 November 2020. 


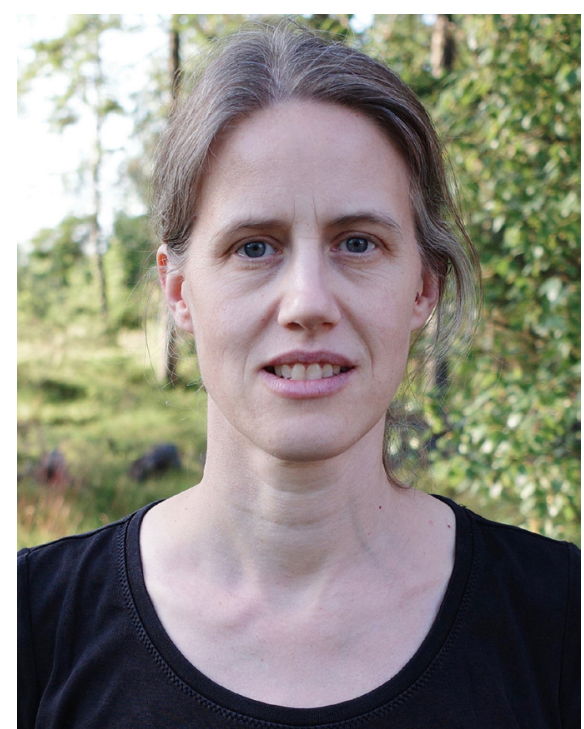

Figure 2 Åsa K Hedman.

ager and renal impairment, along with diastolic and right ventricular dysfunction.

Gal Tsaban (figure 3) is a graduate of Ben Gurion University of the Negev where he completed granted degrees of Medical Doctor and Master in Public Health, and currently is a fellow in Cardiology in Soroka University Medical Center and a clinical researcher at the Department of Public Health in the Ben Gurion University of the Negev. Dr Tsaban's research focuses on hormonal, metabolic, cardiovascular, pericardial-adiposity and electrophysiological changes under distinct lifestyle interventions among people with obesity. The main motivation of Dr Tsaban's research stems from his strong will to improve and promote primordial and primary prevention of cardiovascular diseases among at-risk people with different phenotypes of obesity.

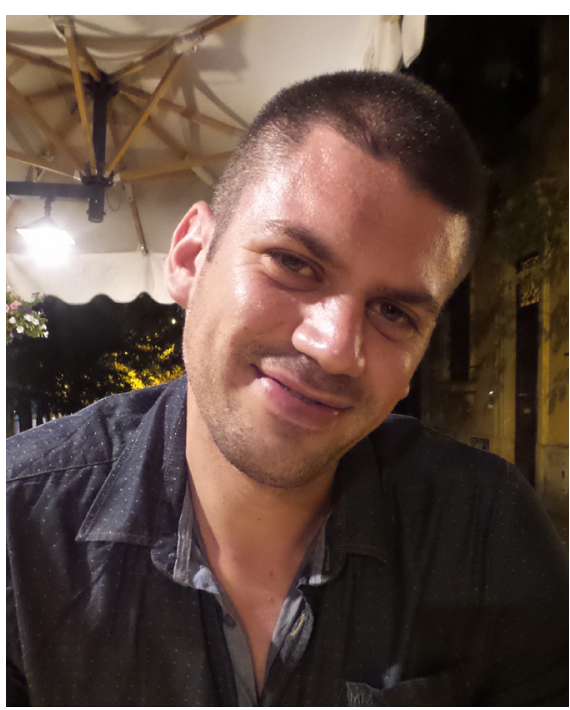

Figure 3 Gal Tsaban.

In this randomised controlled clinical trial including 294 participants with obesity or dyslipidaemia, both the Mediterranean and the greenMediterranean diets had a beneficial effect on cardiometabolic state during the dietary weight loss induction phase. The green Mediterranean diet provided further significant and clinically meaningful improvement in cardiovascular risk reduction compared with the Mediterranean diet, specifically in terms of central adiposity regression, improved lipid profile and systemic inflammation reduction. The results of this study suggest that a green Mediterranean diet, lower in meat and supplemented with green plants, may amplify beneficial cardiometabolic effects of the Mediterranean diet and thus has potential importance in the promotion of primary cardiovascular prevention.
Join me in congratulating the Best Research Paper winner and finalists for their excellent contributions to clinical cardiology!

Contributors $\mathrm{CMO}$ is the sole author.

Funding The authors have not declared a specific grant for this research from any funding agency in the public, commercial or not-for-profit sectors.

Competing interests None declared.

Patient and public involvement Patients and/ or the public were not involved in the design, or conduct, or reporting, or dissemination plans of this research.

Patient consent for publication Not required.

Provenance and peer review Commissioned; internally peer reviewed.

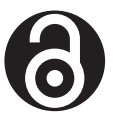

\section{OPEN ACCESS}

Open access This is an open access article distributed in accordance with the Creative Commons Attribution Non Commercial (CC BY-NC 4.0) license, which permits others to distribute, remix, adapt, build upon this work non-commercially, and license their derivative works on different terms, provided the original work is properly cited, appropriate credit is given, any changes made indicated, and the use is non-commercial. See: http://creativecommons.org/ licenses/by-nc/4.0/

(C) Author(s) (or their employer(s)) 2021. Re-use permitted under CC BY-NC. No commercial re-use. See rights and permissions. Published by BMJ.

D) Check for updates

To cite Otto CM. Heart 2021;107:1600-1601.

Published Online First 4 August 2021

Heart 2021;107:1600-1601.

doi:10.1136/heartjnl-2021-320077

\section{ORCID iD}

Catherine M Otto http://orcid.org/0000-0002-05279392 